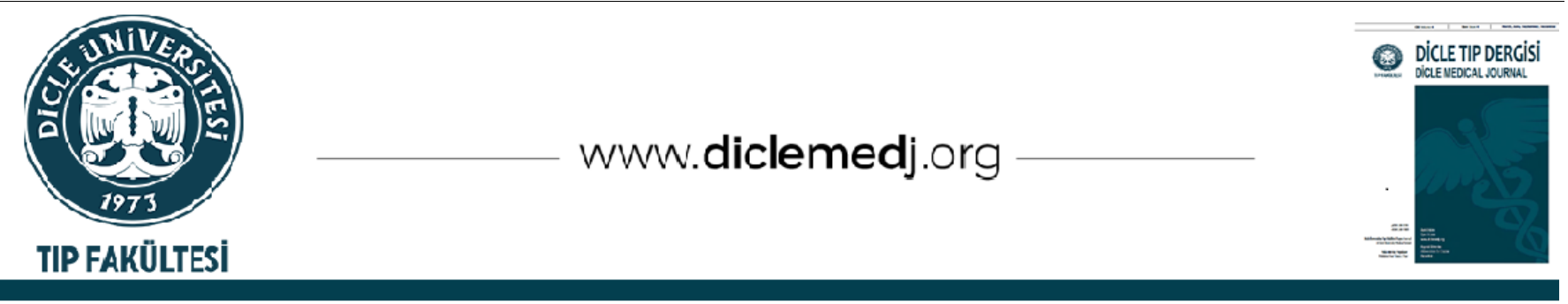

\title{
Opere Pankreas Adenokanserli Hastalarda Kemoterapiye Kemoradyoterapi Eklemenin Katkısı
}

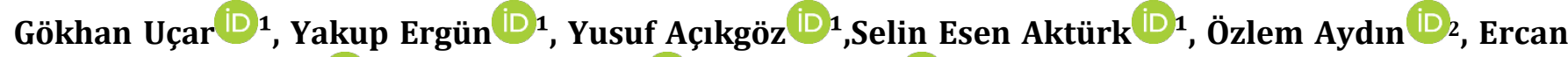 \\ Aydın Karahaliloğlu ${ }^{D}$, İrem Sarıcanbaz ${ }^{D}{ }_{3}$, Doğan Uncu ${ }^{D} 1$
}

1 Sağlık Bakanlığı, Ankara Şehir Hastanesi, Tıbbi Onkoloji, Ankara, Türkiye

2 Sağlık Bakanlığı, Dışkapı Yıldırım Beyazıt Eğitim ve Araştırma Hastanesi, Tıbbi Onkoloji, Ankara, Türkiye

3 Sağlık Bakanlığı, Ankara Şehir Hastanesi, Radyasyon Onkolojsi, Ankara,Türkiye

Geliș: 28.08.2020; Revizyon: 14.10.2020; Kabul Tarihi: 16.10.2020

Öz

Giriş: Pankreas kanserleri kansere bağlı ölüm nedenleri arasında dördüncü sırada yer almaktadır. Genel sağ kalımı iyileştirmek adjuvan kemoterapi (KT) ve kemoradyoterapi (KRT) çalışmaları yapılmaktadır. Biz de pankreas kanserinde retrospektif olarak adjuvan tedavide kemoradyoterapinin etkisini araştırmayı amaçladık.

Yöntemler: Ocak 2010 ve Aralık 2017 tarihleri arasında merkezimizde pankreas kanseri nedeniyle opere edilen ve sonrasında adjuvan tedavi verilen 90 hastanın verileri retrospektif olarak tarandı. Hasta dosyalarından yaş, cinsiyet, ECOG performans durumu, vücut kitle indeksi (VKİ), evre, adjuvan dönemde aldığı tedaviler, KRT alıp almadığı, incelenerek kayit edildi.

Bulgular: Çalışmaya toplam 46 hasta dahil edildi. KRT kolunda ortanca GSK 16,9 ay (7,8-2,63 ay) iken KT kolunda ise $17,6$ ay olup iki grup arasında istatistiksel olarak anlamlı fark saptanmadı( $p=0,875)$. Ortanca DFS,KRT kolunda 12,2 ay iken KT kolunda 7,2 ay saptandı(p:0,3).

Tartışma: Sonuç olarak, literatürde yapılan son çalışmalarla uyumlu olarak bizim çalışmamızda da pankreas kanserli hastalarda adjuvan tedavide kemoterapiye kemoradyoterapi eklemenin genel sağ kalım ve hastalıksız sağ kalıma katkısı gösterilemedi.

Anahtar kelimeler: pankreas, kemoterapi, kemoradyoterapi, adjuvan, kanser

DOI: 10.5798/dicletip.850481

Correspondence / Yazışma Adresi: Gökhan Uçar, Ankara Şehir Hastanesi, Tıbbi Onkoloji Kliniği, Ankara, Türkiye e-mail: gokhanucar_1@hotmail.com 


\title{
The Contribution of Adding Chemoradiotherapy to Adjuvant Chemotherapy in Pancreatic Cancer Patients
}

\begin{abstract}
Introduction: Pancreatic cancers rank fourth among the causes of cancer-related death. Adjuvant chemotherapy (CT) and chemoradiotherapy (CRT) studies are conducted to improve overall survival. We aimed to investigate the effect of chemoradiotherapy in adjuvant therapy retrospectively in pancreatic cancer.
\end{abstract}

Method: The data of 90 patients who were operated in our center for pancreatic cancer between January 2010 and December 2017, and who were given adjuvant treatment afterwards, were retrospectively reviewed. Treatments were recorded by examining whether they received CRT.

Results: A total of 46 patients were included in the study. While the median GSK in the CRT arm was 16.9 months (7.82.63 months), it was 17.6 months in the CT arm and there was no statistically significant difference between the two groups ( $\mathrm{p}=0.875)$. 7.2 months were detected in the CT arm (p: 0.3)

Conclusion: Consequently, in our study, in accordance with the latest studies in the literature, the contribution of adding chemoradiotherapy to chemotherapy in adjuvant therapy in patients with pancreatic cancer, overall survival and disease-free survival could not be demonstrated.

Keywords: pancreas, chemotherapy, chemoradiotherapy, adjuvant, cancer.

\section{GíRiş}

Pankreas adenokarsinomlarında tüm evreler için 5 yıllık genel sağkalım \%10'un altında olup kansere bağlı ölümlerde ise pankreas kanseri ilk dörtte yer almaktadır ${ }^{1,2}$. Bununla birlikte önümüzdeki yıllarda kansere bağlı ikinci en sık ölüm nedeni olacağı tahmin edilmektedir ${ }^{3}$. Hastaların yaklaşık \%20'si rezektabl, \%30'u lokal ileri evre ve \%50'si ise metastatik hastalık aşamasında başvurmaktadır ${ }^{4}$. Negatif cerrahi sınırla yapılmış radikal cerrahi, uzun süreli sağkalım elde etme potansiyeli olan en önemli tedavi yöntemidir5. Bununla birlikte hem lokal hem de uzak nüksler hastaların sağkalımını kısaltmaktadır6. Bu nedenle, genel sağkalımı iyileştirmek için lokal ve sistemik adjuvan tedaviler önerilmektedir. Birçok klinik çalışma, adjuvan kemoradyoterapi (KRT) ve kemoterapinin (KT) etkinliğini değerlendirmiştir ve bu çalışmalarda adjuvan kemoterapinin etkinliği gösterilmekle birlikte, adjuvan KRT'nin potansiyel etkisi hala tartışmalıdır ${ }^{7-9}$.

Postoperatif adjuvan KRT'nin genel sağkalım katkısı Gastrointestinal Tümör Çalışma grubu (GITSG) ve Avrupa Kanser Araştırma ve Tedavi
Örgütü (EORTC) çalışmalarında gözlem koluna karşı gösterilmişken, Avrupa Pankreas Kanseri Çalışma Grubunun (ESPAC) yaptığ çalışmalarda ise gösterilememiştir7,10,11.

Literatürde adjuvan kemoradyoterapinin genel sağkalım gösteren çalışmalar olduğu gibi olmadığını gösteren çalışmalar da mevcut olduğundan dolayı kendi kliniğimizde pankreas kanserli hastaların adjuvan tedavisine KRT eklemenin genel sağkalım katkısı oluşturup oluşturmadığını tespit etmek için bu retrospektif çalışmayı yapmayı amaçladık.

\section{YÖNTEMLER}

\section{Hastalar}

Ocak 2010 ve Aralık 2017 tarihleri arasında merkezimizde pankreas kanseri nedeniyle opere edilen ve sonrasinda adjuvan tedavi verilen 90 hastanın verileri retrospektif olarak tarand. Adjuvan tedavi olarak KT alan ve KT sonrasında KRT alan hastalar çalışmaya alındı.

Dahil etme kriterleri; 18 yaş ve üstü, opere edilmiş ve histolojik olarak kanıtlanmış pankreas adenokarsinomu olması, Eastern Cooperative Oncology Group (ECOG) 
performans durumunun en fazla 2 olması, adjuvan tedavi olarak KT veya KT sonrasinda KRT almış olması, yeterli karaciğer, kemik iliği ve böbrek fonksiyonuna sahip olmak olarak belirlendi. Dahil edilme kriterlerini karşılamayan hastalar çalışma dışı bırakıldı.

Hasta dosyalarından yaş, cinsiyet, ECOG performans durumu, vücut kitle indeksi (VKI), evre, adjuvan dönemde aldığı tedaviler, KRT alıp almadığı, retrospektif olarak incelenerek kayıt edildi. Toksisite verileri yetersiz olduğundan toksisite analizi yapılamadı.

\section{Prosedür}

KT kolundaki hastalara, gemsitabin 1200 $\mathrm{mg} / \mathrm{m} 2$, 1. ve 8 . günler uygulanmak üzere 21 günde bir 6 siklus tedavi uygulandı. KRT kolunda ise hastalara gemsitabin $1200 \mathrm{mg} / \mathrm{m} 2$, 1 ve 8 . günlerde olmak üzere 21 günde bir 4 siklus uygulandıktan sonra, haftalık $400 \mathrm{mg} / \mathrm{m} 2$ gemsitabin eşliğinde 28 fraksiyonda toplam 5040 cGy (günde 1 fraksiyon, 180 cGy) KRT uygulandl.

\section{Prognostik Faktör Analizi}

Daha önce yapılmış olan çalışmalardan yola çıkarak genel sağkalıma etkisi olabilecek 10 değişken seçildi. Değişkenler iki kategoriye ayrıldı; cinsiyet (erkek veya kadın), sigara (evet veya hayır), lokalizasyon (baş veya gövdekuyruk), rezeksiyon tipi (R0 veya R1), lenfovasküler invazyon (var veya yok), lenf nodu pozitifliği (var veya yok), T evresi (2 veya 3 ), CEA düzeyi (<5 veya $\geq 5$ ), diferansiasyon durumu (iyi-orta veya kötü), CA 19-9 düzeyine göre ( $<37$ veya $\geq 37)$.

\section{İstatistiksel Analiz}

Analizi yapılan tedavileri aldıkları gün ile ölüme veya son vizite kadar geçen süre genel sağkalım, hastaların ameliyat tarihlerinden hastalık nüksüne kadar geçen süre hastalıksız sağkalım olarak belirlendi.

Çalışmada elde edilen bulgular değerlendirilirken istatistiksel analizler için
SPSS 22.0 programı kullanıldı. İki grup arasındaki özelliklerin farklılıkları Pearson kikare veya Fisher's exact testi ile analiz edildi. Sağkalım analizi Kaplan-Meier yöntemi ile analiz edildi. Sağkalım süreleri \%95 güven aralığında (GA) belirlenmiştir. Çoklu değişkenli analizler için Cox regresyon testi kullanıldı. $p$ $<0.05$ olan değerler istatistiksel olarak anlamlı kabul edildi. Bu çalışma için Ankara Şehir Hastanesi 1 Nolu Klinik Araştırmalar Etik Kurul Başkanlığı'ndan E1-20-256 sayı numarası ile etik kurul onayı alınmıştır.

\section{BULGULAR}

Çalıșmaya toplam 46 hasta dahil edildi. KRT kolunda 27 hasta $(\% 63,1)$, KT kolunda ise 19 hasta $(\% 36,9)$ vardl. Erkek hastaların 16'sı (\%64) KRT kolunda, 9'u (\%36) ise KT kolunda, kadın hastaların ise 13'ü $(\% 61,9)$ KRT kolunda, 8'i $(\% 38,1)$ ise KT kolunda idi. Ortanca yaş her iki çalışma kolunda da 64,6 yıldı (46-77). Kemoterapi kolundaki hastaların tamamı (n:17) adjuvan tedavide 6 siklus gemsitabin alırken, KRT kolundaki hastaların tamamı adjuvan olarak 4 siklus gemsitabin alındıktan sonra radyoterapi ile eş zamanlı haftalık $400 \mathrm{mg} / \mathrm{m} 2$ gemsitabin ald.

Hastaların 39'unda $\quad(\% 82,9)$ tümör lokalizasyonu pankreas baş kısmı iken 8 hastada $(\% 17,1)$ tümör lokalizasyonu gövdekuyruk bölgesiydi. Tümör lokalizasyonu baş bölgesi olan 25 hasta $(\% 64,1)$ KRT kolunda iken 14 hasta $(\% 35,9)$ KRT almayan kolda idi. Tümör lokalizasyonu gövde-kuyruk olan 4 hasta $(\% 57,1)$ KRT kolunda iken 3 hasta $(\% 42,9)$ hasta KT kolunda idi. Negatif cerrahi sınır ile rezeksiyon yapılan 22 hasta $(\% 59,5)$ KRT kolunda iken 15 hasta $(\% 40,5)$ KT kolunda idi. Bazal hasta özellikleri Tablo I'de verilmiştir.

Çalışmamızın ortanca takip süresi 17 aydı (670). Takipte KRT kolundaki hastaların \%72'sinde nüks gelişirken KT kolundaki hastaların \%73'ünde nüks gelişti $(p=0.95)$. Nüks gelişen hastalar arasında iki grup arasında 
istatistiksel olarak fark saptanmadı. Takipte KRT kolundaki hastalarm \%17'sinde lokorejyonel nüks \%73'ünde ise uzak metastaz gelişirken, KT kolundaki hastaların \%18'inde lokorejyonel nüks, $\% 82$ 'sinde de uzak metastaz gelişti $(\mathrm{p}=0.90)$.

Tablo I: Bazal Hasta Özellikleri

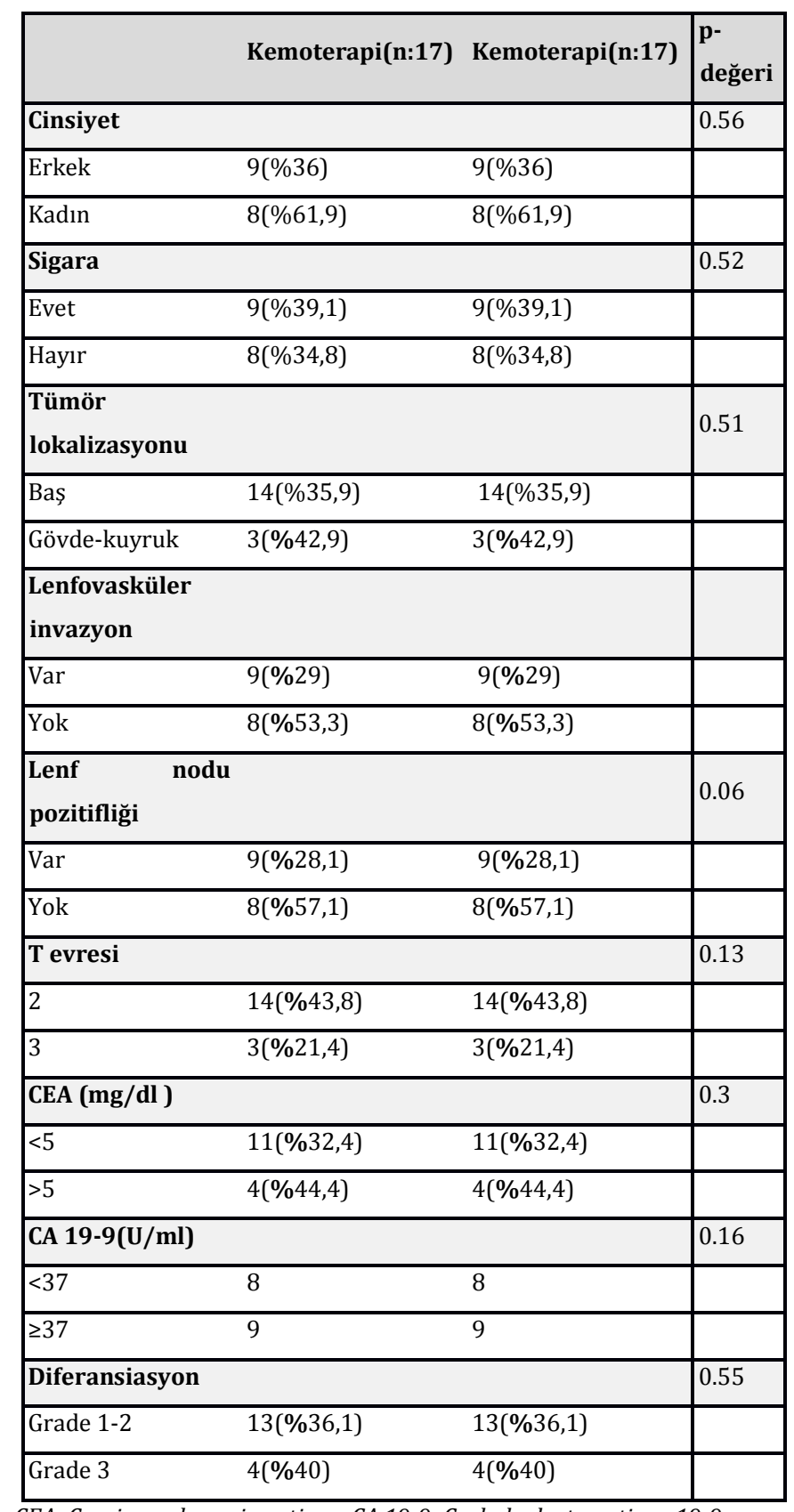

CEA: Carcinoembryonic antigen, CA 19-9: Carbohydrate antigen 19-9

Kemoradyoterapi kolundaki hastalarda sırası ile karaciğer, periton ve akciğer metastazı gelişme oranları \%70, \%15, \%31 iken KT kolundaki hastaların ise $\% 90, \% 0$ ve $\% 20$ idi. Metastaz gelișen bölgeler arasında iki grup arasında istatistiksel olarak fark saptanmadı.

Kemoradyoterapi kolunda ortanca genel sağkalım 16,9 ay iken KT kolunda ise 17,6 ay olup iki grup arasında istatistiksel olarak anlamlı fark saptanmadı ( $\mathrm{p}=0.87)$ (Şekil 1). Ortanca hastalıksız sağkalım KRT kolunda 12,2 ay iken kemoterapi kolunda 7,2 ay idi. Aradaki 5 aylık fark istatistiksel olarak anlamlı değildi $(\mathrm{p}=0.32) \quad$ (Şekil 2). Yüksek riskli grupta sayılabilecek lenf nodu pozitif grupta KRT kolunda genel sağkalım 16 ay iken KT kolunda 10 ay olmasına rağmen bu farkta istatistiksel olarak anlamlı değildi ( $\mathrm{p}=0.67)$.

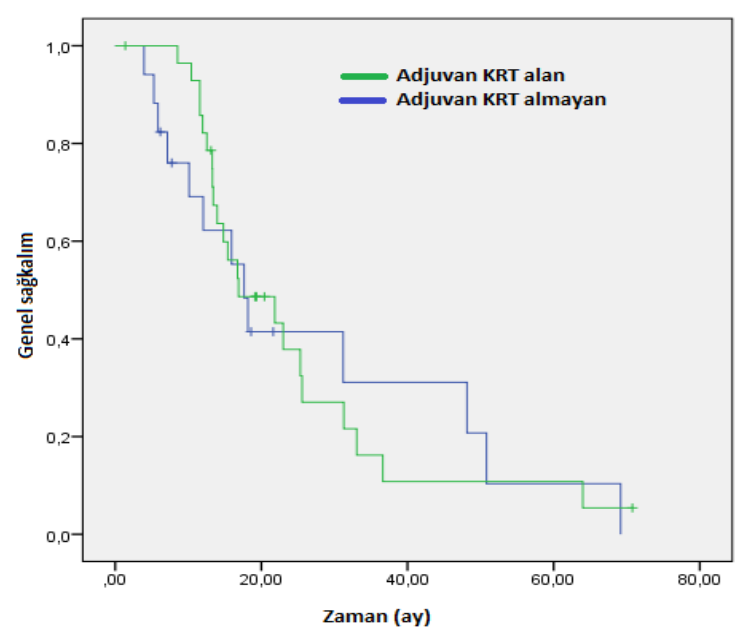

Şekil I: Genel Sağkalım Eğrileri

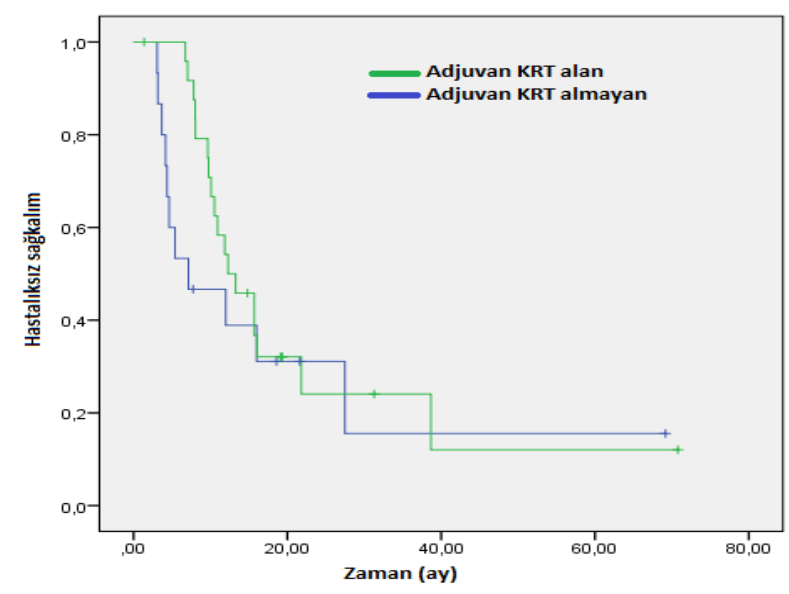

Şekil II: Hastalıksız Sağkalım Eğrileri 


\section{TARTIŞMA}

Çalışmamızda opere pankreas kanserli hastalarda adjuvan KT'ye KRT eklemenin hem genel sağkalım hem de hastalıksız sağkalım açısından anlamlı katkısının olmadığı görüldü. Lenf nodu pozitif hasta grubunda numerik olarak KRT kolunda 6 aylık bir fark olmasına rağmen bu fark istatistiksel olarak anlaml değildi.

Adjuvan KRT'nin pankreas kanserindeki ilk çalışmaları tedavisiz gözlem kollarına karşı yapılmıştır. Pankreas kanserinde adjuvan KRT'nin değerlendirildiği ve toplam 46 hastayı içeren GISTS çalışmasında hastalar izlem ve KRT koluna randomize edildi. KRT kolundaki hastalara RT eşzamanlı 5-FU bolus $(500 \mathrm{mg} / \mathrm{m} 2$ /gün) uygulandı. Ortanca genel sağkalım KRT kolunda 21.0 ay iken izlem kolunda 10.9 ay saptand $\quad(p=0.03) 11$. Pankreas kanseri nedeniyle opere edilen 218 hastanın dahil edildiği EORTC-40891 çalışmasında da hastalar izlem kolu ve KRT koluna randomize edilmişlerdi. $\mathrm{Bu}$ çalışmanın GISTS çalışmasından farkı KRT sırasında bolus 5-FU yerine $25 \mathrm{mg} / \mathrm{kg} /$ gün infüzyonel 5 -FU kullanılmasıydı. Bu çalışmada da ortanca genel sağkalım KRT kolunda daha uzun saptandı ancak fark istatistiksel olarak anlamlı değildi (sırasıyla; 17,1 ay ve 12,6 ay, $p=0.09)^{12}$.

Günümüzde opere pankreas kanserinde adjuvan kemoterapi standart tedavi olduğundan KRT çalışmalarında hastalar izlem kolu yerine adjuvan KT kolu ile karşılaştırılması daha uygun bir çalışma şekli olacaktır. Bu nedenle KRT ile ilgili ilk çalışmaların aksine hastalar KT ile karşılaştırılmıştır. Pankreas kanseri nedeniyle opere olan 289 hastanın değerlendirildiği ESPAC-1 çalışmasında hastalar izlem, KT, KRT ve KRT+KT kolları olmak üzere 4 kola ayrılmıştır7. Kemoterapi kolunda hastalara 5-FU $425 \quad \mathrm{mg} / \mathrm{m} 2$ /gün+Folinik asit $20 \mathrm{mg} / \mathrm{m} 2$ /gün, 5 gün süreyle, 28 günde bir, 6ay süreyle verildi. Kemoradyoterapi kolunda hastalara kemoterapi olarak eş zamanlı 5-FU 500 $\mathrm{mg} / \mathrm{m} 2 /$ gün şeklinde uygulandı. Çalışmanın sonuçlarına göre $4 \mathrm{kol}$ arasında genel sağkalım açısından fark yoktu. Çalışmanın alt grup analizinde, KT alanlar ile almayanlar veya KRT alanlar ile almayanlar karşılaştırıldı. Bu alt grup analizinde, KT alanlarda ortanca genel sağkalım 20,6 ay, KT almayanlarda 15,5 ay saptand. $\mathrm{Bu}$ fark istatistiksel olarak anlaml iken, KRT alanlarla almayanların karşılaştırılmasında ise ortanca genel sağkalım açısından fark yoktu. Yapılan diğer bir çalışmada ortanca genel sağkalım KRT almayanlarda 11,0 ay iken KRT alanlarda 15,0 ay saptanmış olup fark anlamlı değildi13 ( $\mathrm{p}=0.67)$.

Sonuç olarak literatürde bildirilen son çalışmalarla uyumlu olarak bizim çalışmamızda da pankreas kanserli hastalarda adjuvan tedavide kemoterapiye kemoradyoterapi eklemenin genel sağkalım ve hastalıksız sağkalıma katkısı gösterilemedi.

Etik Kurul Onayı: Bu çalışma için Ankara Şehir Hastanesi 1 Nolu Klinik Araştırmalar Etik Kurul Başkanlığı'ndan E1-20-256 sayı numarası ile etik kurul onayı alınmıştır.

Çıkar Çatışması Beyanı: Yazarlar çıkar çatışması olmadığını bildirmişlerdir.

Finansal Destek: Bu çalışma herhangi bir fon tarafından desteklenmemiştir.

Declaration of Conflicting Interests: The authors declare that they have no conflict of interest.

Financial Disclosure: No financial support was received.

\section{KAYNAKLAR}

1. Danıs R, Bayan K, Yılmaz Ş, Altıntas A. The Pancreatic Cancer Cases in Dicle University Department of Gastroenterology in the Last Ten Years. Dicle Med J. 2004; 31: 58-61. 
2. Ergun Y, Ozdemir NY, Guner EK, et al . Comparison of Gemcitabine monotherapy with Gemcitabine and Cisplatin combination in metastatic pancreatic cancer: a retrospective analysis. J BUON. 2018; 23:116-21.

3. Rahib L, Smith BD, Aizenberg R, Rosenzweig AB, Fleshman JM, Matrisian LM. Projecting cancer incidence and deaths to 2030: the unexpected burden of thyroid, liver, and pancreas cancers in the United States. Cancer Res. 2014; 74:2913-21.

4. Hidalgo M. Pancreatic cancer. N Engl J Med. 2010; 362:1605-17.

5. Gurusamy KS, Kumar S, Davidson BR, Fusai G. Resection versus other treatments for locally advanced pancreatic cancer. Cochrane Database Syst Rev. 2014; CD010244.

6. Hishinuma S, Ogata Y, Tomikawa M, et al. Patterns of recurrence after curative resection of pancreatic cancer, based on autopsy findings. J Gastrointest Surg. 2006; 10:511-8.

7. Neoptolemos JP, Dunn JA, Stocken DD, et al. Adjuvant chemoradiotherapy and chemotherapy in resectable pancreatic cancer: a randomised controlled trial. Lancet. 2001; 358:1576-85.

8. Dobiasch S, Goerig NL, Fietkau R, Combs SE. Essential role of radiation therapy for the treatment of pancreatic cancer: Novel study concepts and established treatment recommendations. Strahlenther Onkol. 2018; 194:185-95.

9. Springfeld C, Jäger D, Büchler MW, et al. Chemotherapy for pancreatic cancer. Presse Med. 2019;48(3 Pt 2):e159-e174.

10. Kalser $\mathrm{MH}$, Ellenberg SS. Pancreatic cancer. Adjuvant combined radiation and chemotherapy following curative resection. Arch Surg. 1985;120:899-903.

11. Further evidence of effective adjuvant combined radiation and chemotherapy following curative resection of pancreatic cancer. Gastrointestinal Tumor Study Group. Cancer. 1987; 59: 2006-10.

12. Klinkenbijl JH, Jeekel J, Sahmoud T, et al. Adjuvant radiotherapy and 5-fluorouracil after curative resection of cancer of the pancreas and periampullary region: phase III trial of the EORTC gastrointestinal tract cancer cooperative group. Ann Surg. 1999; 230:776-82; discussion 782-4.

13. Helvacı K, Üyetürk Ü, Sönmez Ö, Türker İ, Arslan ÜY. Evaluation of Demographic And Clinicopathological Characteristics Of Panreatic Adenocarcinoma Patients. Acta Oncol Tur. 2016;49: 91-101. 